\title{
Improving safety of runway overrun through the correct numerical evaluation of rutting in Cleared and Graded Areas
}

\author{
A. Benedetto*, F. D’Amico, F. Tosti \\ Department of Engineering, University Roma Tre, Via Vito Volterra 62, 00146 Rome, Italy
}

\section{A R T I C L E I N F O}

\section{Article history:}

Received 20 August 2012

Received in revised form 27 April 2013

Accepted 20 September 2013

\section{Keywords:}

Airport safety

Aircraft overrunning

Prediction of rutting

Cleared and Graded Area

LFWD

\begin{abstract}
A B S T R A C T
Aircraft overrun is potentially very dangerous to human life. Statistics show that overrun is mainly due to human errors causing loss of control in wheel alignment, high approach speed, and long touchdown. To prevent such disastrous consequences, advanced material arresting systems are currently being used in the main international airports for construction of Runway Safety Areas (RSAs). Many predictive models have been developed for controlling overrun events: the early reliable numerical models, on the basis of theoretical streamlined assumptions, were gradually replaced. More rigorous models based on Multibody System (MBS) and Finite Element Method (FEM) theories are nowadays much more preferred. These are characterized by high levels of reliability, even though the large number of data required does not always allow an exhaustive description of the domain of analysis. The paper presents an alternative method for predicting rut depths induced by aircraft overrunning. Such method is based on a numerical streamlined model, integrated with measurements from Light Falling Weight Deflectometer (LFWD), to define, section by section, the mechanical properties of soils in Cleared and Graded Areas (CGAs). The method has been validated through in situ tests, showing its high effectiveness and efficiency.
\end{abstract}

\section{Introduction}

In the past decade air transportation traffic has recorded a significant growth, due to new carriers of commercial airlines, competition processes, and technological enhancement. Moreover, a deep increase of low-cost carriers has been observed all over the world. In the case of U.S. airports, such aspect has focused in a first step on the largest airports, moving to second tier airports, once the best opportunities for growth at the largest hubs began to dwindle (Belobaba et al., 2012). In general, the increasing of the number of operations has caused a large number of further problems particularly related to environmental issues, mostly in secondary airports, and safety aspects. In that respect, aircraft overrun is one of the most potentially damaging events. An overrun by definition occurs any time an aircraft passes beyond the end of a runway during an aborted take-off or while landing.

Many accidents related to overrun events have been recorded in international plane crash databases, sometimes with devastating results (PlaneCrashinfo.com Database, 2012). On the 17th of July 2007, an Airbus A-320-233 skidded off the end of the runway at Congonhas Airport (Brasil), across a major roadway and struck a gas station and building, bursting into flames: 187 people, crew including, lost their lives. More recently, on the 22th of May

\footnotetext{
* Corresponding author. Tel.: +3906 57333543; fax: +390657333441

E-mail address: andrea.benedetto@uniroma3.it (A. Benedetto).
}

2010, a Boeing 737-800 crashed while attempting to land in heavy rain at Mangalore-Bajpe (India). The aircraft overran the runway, slid down a ravine into a wooded valley, and burst into flames: 158 people died.

Concerning aircraft overruns and undershoots in Runway Safety Areas (RSAs), 459 international accidents and incidents occurred between 1978 and 2006 have been analyzed (Hall et al., 2008). It is shown that landing overrun events (60\%) occur more frequently than landing undershoots (20\%) or take-off overruns (20\%). Within these critical events, anomalies during accidents and incidents are mostly related to human error, weather, runway conditions, approach procedures, or any number of other conditions or combinations thereof. Information concerning the dynamics of overrun events indicate that in $90 \%$ of cases, the aircraft exits the runway at $36 \mathrm{~m} / \mathrm{s}(118 \mathrm{ft} / \mathrm{s})(70 \mathrm{knots})$ or less.

Moreover, from the analysis of the final resting locations of aircraft after an overrun, it can be noted that most of the overruns $(88 \%)$ stop within a lateral distance of $30.5 \mathrm{~m}$ (100 ft) from the runway centerline, and $304.8 \mathrm{~m}$ (1000 ft) longitudinally from the end of the runway (David, 1990; White and Agrawal, 1993; Wong et al., 2009). Such statistics have been confirmed by further analyses carried out by the Ascend World Aircraft Accident Summary between 1998 and 2007 (e.g., Taylor et al., 2008a; Taylor and Godley, 2008b): a set of 120 runway excursions on landing involving commercial jet aircrafts has been investigated to map the distance that aircraft overran or veered off the runway. Most of the aircrafts 
stopped within $304.8 \mathrm{~m}$ (1000 ft) the runway end, and within the extended runway area.

Safety overrun areas are designed by regulation to provide an additional $304.8 \mathrm{~m}$ (1000 ft) of length to stop overrunning aircrafts. Anyhow, such additional areas are not available in many airports. In these cases, soft ground arresting systems can be employed to decelerate or stop an overrunning aircraft (White and Agrawal, 1993).

In that respect, many efforts have been devoted. In 1975, the Royal Aircraft Establishment experimented the use of urea formaldehyde foam in full-scale tests (Bade, 1969; Barnes, 1974) according to preliminary theoretical studies (Gwynne, 1975). Due to the large costs of such materials, the experiments were untimely left. In 1984, following a landing overrun of a Scandinavian Airlines DC-10 at John Fitzgerald Kennedy International Airport, testing on arresting materials were resumed. Ten years later, the first soft ground arrester was realized (White and Agrawal, 1993).

Nowadays, to minimize the hazards of overruns, the Federal Aviation Administration (FAA) provides the use of soft ground arresters at different bearing capacities whereas the existing pavement length is not suitable to meet runway safety area standards. In most cases, the pavement structure is therefore composed of an arresting layer, protected with a covering material, and placed above a subgrade. During overruns, it is also required to be resistant to deterioration due to aircraft fuels and oils leakage in case of accident (Bennett, 2005).

Arrestor beds can be manufactured with different materials. Cellular concrete is a type of lightweight concrete formed by entraining air into the cement slurry, so that the crushable pre-cast cellular concrete blocks have compressive strengths as the normal weight concrete, even though with lower densities (Marisetty et al., 2008). The effectiveness of gravel beds was assessed by the Royal Aircraft Establishment using the physical similarity and dimensional analysis techniques. Results allowed to accurately predict the distance required to stop aircrafts at a given entry speed (Barnes, 1974). Urea formaldehyde foam is a non-transparent thermosetting resin or plastic, with a chemical structure classified as polymethylene (Jiang et al., 2010; Randall, 1970). Due to its high tensile strength, heat distortion temperature, elongation at break, and volume resistance, good properties in aircrafts arresting have been demonstrated (Gwynne, 1975). Phenolic foam has significant properties such as an excellent fire resistance, no dripping during combustion, and both a low smoke density and toxicity. Moreover, it has high resistance to chemical and solvents (Desai et al., 2007). A phenolic foam bed $207.26 \mathrm{~m}$ ( $680 \mathrm{ft}$ ) long, by $14.63 \mathrm{~m}$ ( $48 \mathrm{ft}$ ) wide, and $0.4572 \mathrm{~m}$ (18 in.) deep was used to check the effectiveness of safely stopping a Boeing 727 aircraft while entering the bed at different runway exit speeds. Results were positive: at $25.7 \mathrm{~m} / \mathrm{s}(84.4 \mathrm{ft} / \mathrm{s})(50$ knots $)$ the aircraft was stopped in $128.02 \mathrm{~m}(420 \mathrm{ft})$, and at $30.9 \mathrm{~m} / \mathrm{s}(101 \mathrm{ft} / \mathrm{s})(60 \mathrm{knots})$ in $164.59 \mathrm{~m}$ $(540 \mathrm{ft})$. No structural damages were registered and the foam was successfully repaired (White and Agrawal, 1993). The Engineered Material Arresting System (EMAS) is characterized by a readily and reliably deformation under the weight of an overrunning aircraft (O'Donnell, 2005). The resulting displacement drag forces are generated as the landing gear burrows through this material, and applied through the traveled distance, as they are friction forces. The resulting work dissipates the kinetic energy of the aircraft until it eventually comes to decelerate the aircraft to a safe stop (Deloach et al., 2009; Lang, 2004). In the past decade, further studies have been developed by the FAA in cooperation with the Engineered Systems, Co. (ESCO) of Logan Township, NJ, to optimize an EMAS design for the specific needs of airfields (Heymsfield and Halsey, 2007).

Arrestor beds are characterized by high costs of construction and maintenance requiring to be improved in order for this type of safety system to be more widely used. Ho and Romero (2009) evaluated the costs of EMAS as used in three U.S. airports: construction costs ranged from 3037 dollar $/ \mathrm{m}^{3}\left(86 \mathrm{dollar} / \mathrm{ft}^{3}\right)$ to 3885 dollar $/ \mathrm{m}^{3}$ (110 dollar $\left./ \mathrm{ft}^{3}\right)$. FAA further studies have confirmed such estimates, with 3249 dollar $/ \mathrm{m}^{3}$ ( $\left.92 \mathrm{dollar} / \mathrm{ft}^{3}\right)$ both for site preparation and bed installation (Lang, 2004). Due to such high costs of construction, the use of arresting materials in Cleared and Graded Areas (CGAs) has proved to be not cost-effective. Therefore, natural soil is nowadays considered as the most efficient material for CGA in most of the airports.

Kirkland et al. (2004) proposed a probabilistic methodology to assess the risk of runway overrun. Moreover, many predictive models for tire-soil interaction and evaluation of the sinkage of aircrafts wheels in soil landing fields have been developed to check the effectiveness of the bearing capacities of CGA subgrades, as well as the bearing characteristics required to decelerate the aircraft in a safe stop distance.

Richmond et al. (1968) proposed a mathematical model validated through experimental results on the basis of four primary factors causing soil rutting and drag. Such factors consist of a tire spring rate, a soil load deflection relation, a drag inertia force, and a lift inertia force. Information about active and reactive forces, soil properties, in terms of CBR index and HRB-AASHTO classification category, and tire characteristics are required. The model has been further refined (Coutermarsh, 2007; Crenshaw, 1972; Shoop et al., 2001). The growth of computational resources allowed the development of more rigorous mathematical models. The Multibody System (MBS) simulation tools allow to investigate the dynamic behavior of the vehicle, tire, and soil system (Gibbesch, 2002). The simulation of tire-soil interaction by means of multibody tools is based on analytical modeling, and specific measurable parameters are required to describe the physical soil behavior. The tire-soil contact area is represented by analytical approaches. This allows to to reach a relatively good approximation of the real contact conditions. Anyhow, the description of physical soil behavior is affected by many problems due to its non-deterministic properties.

Other approaches treated the problem of tire-soil interaction with the method of finite elements (FEM) (Liu and Wong, 1996). These models allow a very fine discretization and an accurate simulation of the deformations of either tire or soil. In any case, this modeling approach generally needs a large amount of computation time, thereby making the MBS mainly used in the modeling of tiresoil interaction. The Institute of Robotics and Mechatronics also demonstrated a high effectiveness in the combined use of such two approaches. In particular, MBS was used for modeling the landing gear and fuselage, and the FE method additionally calculated the tire and soil deformations (Liu and Wong, 1996).

Within these numerical models, soils mechanical properties can be modeled using different survey instruments and methods. The California Bearing Ratio $(C B R)$ is a strength parameter arising from punctual and destructive tests. This requires a large number of samples and several days for testing (American Society for Testing and Materials, 2009). In that respect, non-destructive technologies are nowadays increasingly being used. The light falling weight deflectometer (LFWD) is an instrument widespreadly used both for construction quality control and road construction. It was developed in Germany as an alternative in situ device to the plate load test (Kavussi et al., 2010; Lee et al., 2004). Basically, the LFWD consists of a loading device that produces a defined load pulse, a loading plate, and a set of geophone sensors to measure the deflections. The LFWD elastic modulus can be therefore calculated from the applied load pulse and the recorded deflection. Several studies have been carried out in the last few years to assess the LFWD measurements and evaluate as these can be affected by some relevant parameters such as moisture content, temperature, 
compaction, and grading; further, the effective spatial domain of influence of the LFWD has been analyzed in different instrument configurations (Benedetto et al., 2012). Recently, with the aim to correlate the values of elastic modulus to the LFWD measurements and to the CBR indexes of soils, the U.S. Department of the Air Force (2008) has developed field tests for stabilized soil-surfaced airfields.

\section{Objectives}

The main objective of this work is to provide an improved numerical method for quantitative predictions of deformation and rutting in soils, in order to increase the safety conditions of airplane while landing and taking-off. The overall approach needs a restrict number of information to initialize the numerical model, particularly if compared to the larger number of data required to implement other more complex mathematical models. Therefore, time required for running tests and data-processing is lower. Concerning the effectiveness of such method, the increase of reliability can be achieved by using detailed data from the LFWD device. This allows to collect the mechanical properties of soils, section by section. The reliability of the process has been validated through in situ tests by simulating overrun events along airport CGAs.

The improvements of the numerical model integrated with information from the above mentioned non-destructive technique will be discussed in the next chapters.

\section{Theoretical background}

\subsection{Background}

The mathematical model used herein was first approached by Richmond et al. (1968). It was based on empirical results that related rutting and rolling resistance in cohesive soils with velocity by using a "dynamic mobility number" $\Omega^{\prime}$, empirically developed at the U.S. Army's Waterways Experiment Station (WES). The model was subsequently refined by Crenshaw (1972) and discussed in Shoop et al. (2001). Recently, the approach has been validated on non-cohesive soils, in particular on dry soils (Coutermarsh, 2007). Some difficulties have been experienced in the use of the model as a predictive tool, particularly for its high sensitivity to the velocity (Beaty, 1975) and its reliance on empirical coefficients, not well-defined and thus difficult to be determined for other tires and load configurations.

\subsection{Tire-soil interaction model}

We propose herein an improvement of the numerical approach for rutting prediction in both cohesive and incoherent soils. The analyses were focused on the most critical situations causing deep sinkage. We considered the single tire as a pattern for the applied loads although they were not uniformly distributed on the soil. In fact, in the cases of Airbus and Boeing the rear tires support most of the aircraft weight (94-95\%) during take-off maneuver (Boeing Commercial Airplanes, 1992). Moreover, due to their arrangement, the tire passage always occurs in not compacted soils.

\subsubsection{Definition of the general characteristics of soil and tires geometry}

The most important soil properties to be considered are the strength characteristics used to define the test conditions, the dimensionless quantities which arise from the analysis of the tire-soil system, and the parameters used to classify different types of soil.
Basically, strength characteristics are related to the Cone Index $(C I)$, measured on the field using either a standard penetrometer with a $3.2258 \times 10^{-4} \mathrm{~m}^{2}\left(0.5 \mathrm{in}^{2}\right)$ base area $30^{\circ}$ cone, or an airfield cone penetrometer having a $1.2903 \times 10^{-4} \mathrm{~m}^{2}\left(0.2 \mathrm{in}^{2}\right)$ base area $30^{\circ}$ cone. $\mathrm{Cl}$ is obtained by dividing the applied force by the cone base area. Penetrometer measurements can be correlated to the corresponding CBR indexes. Richmond et al. (1968) used a CI to $C B R$ ratio of 50:1 for conversion, subsequently modified by Shoop et al. (2008) through the following empirical relationship that is not specific to soil from one test site:

$C B R=a C I^{b}$

where $a$ and $b$ are two dimensionless regression coefficients depending on the type of soil.

Concerning cohesive soils, $G$ is defined as the average rate of increase in $\mathrm{Cl}$ values over a depth equal to the tire width with units of psi/in. The main parameters, which relate tire properties to soil conditions, are included in same dimensionless mobility numbers. In that respect, the WES has developed equations both for cohesive and frictional materials. In particular, the WES sand mobility number $\Omega_{\mathrm{s}}$ is defined as:

$\Omega_{s}=\frac{G(b d)^{\frac{3}{2}}}{F_{t}}\left(\frac{\delta_{t}}{h_{t}}\right)$

where $b$ is the tire width in inches, $d$ is the tire diameter in inches, $F_{t}$ is the load on the tire in pounds, $\delta_{t}$ is the tire deflection in inches, and $h_{t}$ is the tire section height in inches.

In case of clay, the mobility number $\Omega_{c}$ is defined as:

$\Omega_{c}=\frac{C I(b d)}{F_{t}} \frac{\left(\delta_{t}\right)^{1.2}}{\left(h_{t}\right)^{\frac{1}{2}}}(0.534)$

where the exponents 1.2 and $1 / 2$ take into account the inflation pressure of the wheels.

The rut depth is defined as the distance from the undisturbed soil surface to the bottom of the rut (Coutermarsh, 2007; Crenshaw, 1972; Richmond et al., 1968; Shoop et al., 2001), as shown in Fig. 1.

Experiments carried out by Crenshaw (1972) have shown that the deformation of soil decreases as the load application rate in creases. On the contrary, when a rolling tire comes to rest, it will induce a greater depth during the first few seconds after stopping. Such effect takes place at too low speeds to be considered as inertial resistance of the soil particles; therefore, it is attributed to time-dependent propagation of inter-granular friction and strains.

Richmond et al. (1968) made plate sinkage tests to evaluate a dimensionless dynamic factor $D$ which attenuates the sinkage proportionally to the load application rate when multiplied by static sinkage. The empirical equation is:

$D=1+1.34 e^{-1.27 t_{p}}$

where $t_{p}$ is the pulse loading time in seconds, inversely proportional to increasing values of tire speed. From Eq. (4) it is evident that such

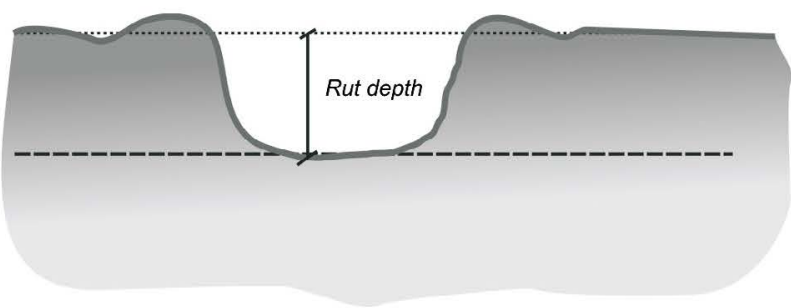

Fig. 1. Rut depth description from Coutermarsh (2007), Crenshaw (1972), Richmond et al. (1968), and Shoop et al. (2001). 
relationship has to be refined at lower velocity values: at zero speed, $t_{p}$ approaches infinity, causing static and dynamics conditions of sinkage not experimentally proved. In this regard, the dynamic factor has been recalibrated in this study to better represent the event at lower velocities, with a discriminant value of $20.6 \mathrm{~m} / \mathrm{s}(67.5 \mathrm{ft} / \mathrm{s})(40$ knots $)$. Two equations have been proposed:

for $V \geq 40$ knots : $D=1+1.34 e^{-1.27 t_{p}}$

for $V<40$ knots : $D=1.58-V \cdot 0.0145+1.34 e^{-1.27 t_{p}}$

where $V$ is expressed in knots.

The dynamic factor $D$ allows to correct Eqs. (2) and (3) in order to take into account the dynamic aspects of rutting. $\Omega^{\prime}$ equals:

$\Omega^{\prime}=\left(\frac{D}{1.6}\right) \Omega$

The tire geometric properties in Fig. 2 show the most important features considered into the soil sinkage calculations through Eqs. (2) and (3). These have been found to be the tire diameter $(d)$, width (b), section height $\left(h_{t}\right)$, and deflection under load $\left(\delta_{t}\right)$.

Tire deflection is defined as the reduction of the section height due to the combination of the load applied on the wheel with the conditions of tire inflation.

Soil is deformed by pressure applied inside the tire footprint and is not-linearly proportional to the magnitude of the applied pressure. In this regard, many tests have shown that pressure in soils is not uniformly distributed under a loaded surface, although the load consists of flat plates. It is usual to divide the pressure under a rolling tire into a normal pressure perpendicular to the local surface of the tire, and a shearing stress along the circumference of the tire. A constant value of pressure is assumed across the width of the tire, although this issue is not verified in case of rigid wheels. The integral of the pressure over the tire-soil contact area, must be equal to the load applied on the wheel.

The tire footprint length $L_{t}$ is expressed in inches. It is used to calculate the inertial lift and to determine the pulse loading time of the soil for assessing the dynamic factor. This length is:

$L_{t}=2\left(d\left(\delta_{t}+Z_{s}\right)-\left(\delta_{t}+Z_{s}\right)^{2}\right)^{\frac{1}{2}}$

where $Z_{s}$ is the rut depth in inches.

The load applied to the soil surface is distributed over the surface proportionally to the local tire footprint pressure. It is equal and opposite to the vertical load applied at the wheel axle. This is assumed to be constant for a freely rolling wheel on a smooth surface. Local undulations in the surface directly affect the vertical

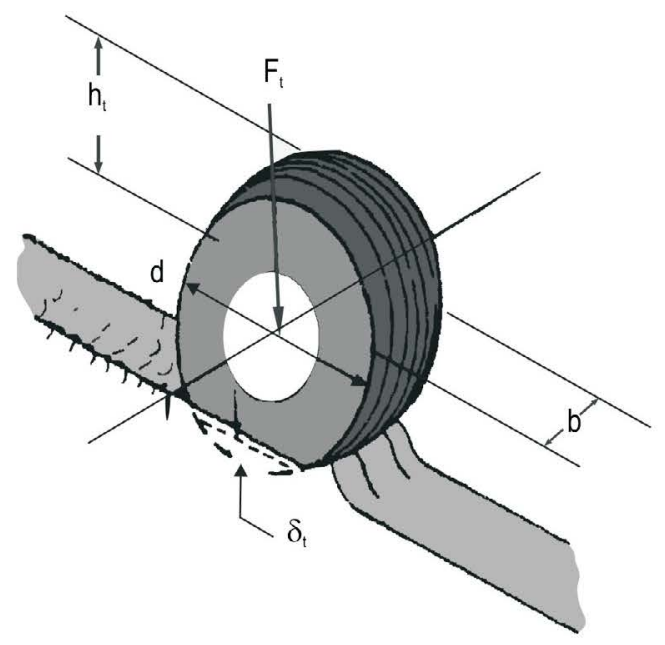

Fig. 2. Tire geometric properties. load in proportion to the amplitude of the undulations. In general, any factor that abruptly affects the rut depth, such as soil strength variations with distance traveled, brake application, and brake release, can change vertical load.

Soil deformation originates from the initial point of contact on the tire with the soil surface, until the axle passes over this contact point. The load history in the soil of such particular point is a pulse, and its duration is proportional to the wheel forward speed $V$. The derivative of this pressure versus time pulse is the instantaneous load application rate. As a first approximation, pulse time is taken as:

$t_{p}=L_{t} / V$

At higher speed levels, Eq. (8) may approach a value of:

$t_{p}=L_{t} / 2 \mathrm{~V}$

as the tire is increasingly supported on the front half of the footprint length. In both Eqs. (8) and (9), $V$ is expressed in in./s.

\subsubsection{The numerical model}

Horizontal and vertical inertia forces, respectively drag and lift, have been combined with empirical mobility number load sinkage equations in the model represented in Fig. 3.

In case of tire-cohesive soils interaction, the model consists of four forces acting through springs, in order to better represent a load deflection relationship (Crenshaw, 1972; Richmond et al., 1968). Such spring forces can be separately considered: the tire spring and the drag interaction spring act in a direction to increase rut depth. Conversely, the soil resistance and the inertia lift act in a direction to reduce rut depth. Solution is by iterative calculation of a steady state equilibrium force.

The schematization has been modified to be suitable to frictional materials, as these are not affected by soil inertia forces and drag loads (Coutermarsh, 2007).

\subsubsection{Case of cohesive clay materials}

Four main forces are considered in case of fine-grained soils.

Fig. 4 shows the non-linear load deflection curve representing the tire spring. It is assumed that no damping is associated with this spring, and in order to determine deflections or forces, the load is assumed to be punctually applied. Experimental results have demonstrated that higher pressure values required greater loads to achieve the same rut depths.

The soil spring is represented by an empirical mobility number relationship. Such equation shows that rut depth, expressed in inches, decreases with the increasing of the mobility number as:

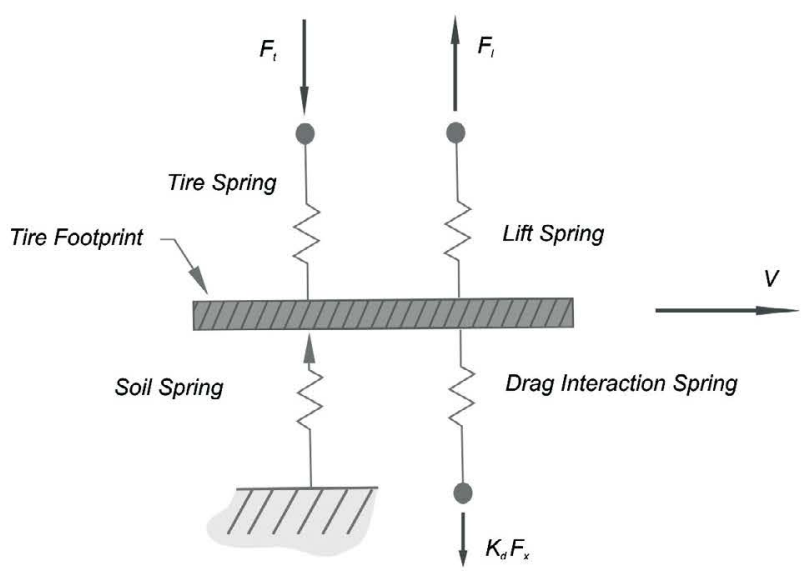

Fig. 3. Diagram of the tire-soil interaction model from Crenshaw (1972). 


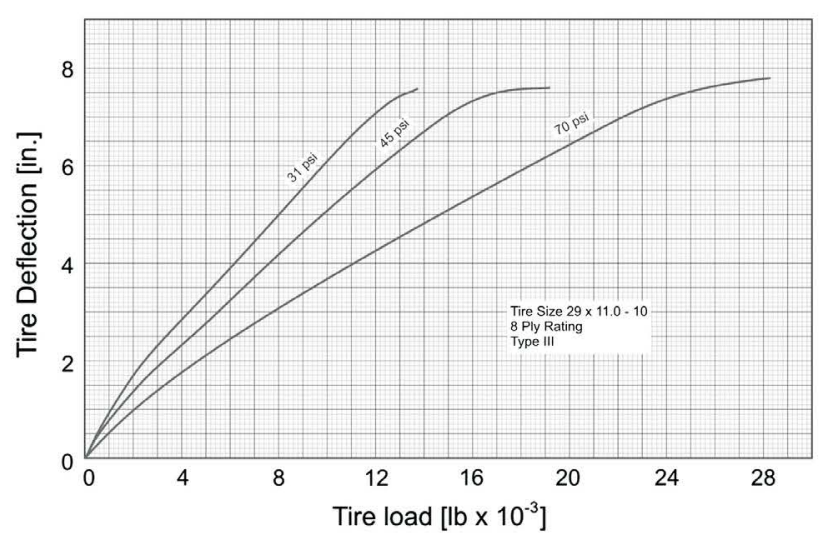

Fig. 4. Tire load versus tire deflection from Crenshaw (1972).

$\Delta Z_{\text {s soils pring }}=\left(\frac{0.1208}{\Omega_{c}^{\prime}-0.9468}-0.0095\right) d$

The drag interaction spring is based on the hypothesis that the equilibrium rut depth is dependent both on the wheel vertical loading and on the horizontal drag load reaction in the soil. Therefore, these quantities are inter-related and cannot be determined independently. The equation representing the incremental rut depth is expressed in inches and equals:

$\Delta Z_{s \text { drag }}=\frac{K_{d} F_{x}}{C I^{0.8}}$

where $K_{d}$ is an empirical drag interaction constant in in./lb., as a function of tire deflection, and $F_{X}$ is the drag force in pounds. This latter is defined by the drag load equation:

$F_{x}=\left(\mu_{0}+\frac{Z_{S}}{L_{t}}\right) F_{t}+\frac{1}{2} \rho b Z_{S} C_{D} V^{2}$

where $\mu_{0}$ is a dimensionless rigid surface rolling resistance coefficient, $F_{t}$ is the vertical tire force in pounds, $\rho$ is the soil density in lb. s. ${ }^{2} /$ in. $^{4}, C_{D}$ is a dimensionless impingement drag coefficient.

Concerning the lift spring, the soil inertia force increases proportionally to the square of the forward velocity of the wheel. This force cannot be considered a lift in the sense of circulation about an airfoil, as it is similar to the force which separates a hydroplaning tire from the pavement surface. The force generated on the tire, expressed in pounds, is defined by the inertia lift force equation:

$F_{l}=\frac{1}{2} \rho b L_{t} C_{L} V^{2}$

where $C_{I}$ is a dimensionless inertial lift coefficient. Thus, the net force on the tire, in pounds, causing penetration into the soil is:

$F_{n e t}=F_{t}-\frac{1}{2} \rho b L_{t} C_{L} V^{2}$

It is defined as the difference between the applied force and the soil resistance to deformation, until depth equilibrium is reached. Moreover, as the rut depth is proportional to the net force applied, a rut depth increment is proportional to some factor times the inertia force. This issue is considered by the lift spring, expressed in inches, as follows:

$\Delta Z_{\text {slift }}=\frac{K_{l} F_{l}}{C^{0.8}}$

where the constant $K_{l}$, expressed in in./lb., is in the form of a reciprocal spring constant; it allows to convert the force into a deflection.

The summation of deflection components gives the following rut depth equation expressed in inches:
$Z_{\mathrm{s}}=\Delta Z_{\text {ssoilspring }}+\Delta Z_{\text {sdrag }}-\Delta Z_{\text {slift }}$

3.2.4. Case of non-cohesive sandy materials

The proposed model has been modified to be suitable for rutting assessment in sandy materials (Coutermarsh, 2007). As in the case of cohesive materials, rut depth increases across the lowest velocities up to a maximum value and subsequently decreases with increasing velocities. The threshold of velocity separating those two different behaviors is defined by:

$V_{p}=1.2 p$

where $V_{p}$ is the planing velocity in $\mathrm{ft} / \mathrm{s}$ and $p$ is the tire pressure in psi. from:

With regard to the forces involved, the tire drag is computed

$F_{x}=\frac{D_{T}}{F_{t}} F_{t}+\frac{1}{2} \rho_{s} b Z_{S} C_{D} V^{2}$

where $\frac{D_{T}}{F_{T}}$ is the low-speed drag coefficient, $\rho_{S}$ is the sand density in lb.s. ${ }^{2} /$ in. $^{4}$, and $V$ is the tire velocity in in./s. In Eq. (18) the variables before the plus sign represent a low-speed term, and those after are a high-speed term. It is possible to write $\frac{D_{T}}{F_{T}}$ in terms of $\Omega_{S}^{\prime}$ as follows:

$\frac{D_{T}}{F_{t}}=\frac{0.6490}{\Omega_{s}^{\prime}-2.2222}+0.366$

$C_{D}$ coefficient depends on the ratio between the ground velocity $V$ and the planing velocity $V_{p}$ : for ratio values between 0 and 0.9 , a constant value of $C_{D}(1.72)$ can be observed. Conversely, for ratio values greater than 0.9 , decreasing values of $C_{D}$ are registered.

The tire sinkage is therefore defined by the analogous expression of Eq. (10) used for describing the $\Delta Z_{\text {ssoilspring }}$ in cohesive clay materials:

$Z_{s}=\left(\frac{0.3439}{\Omega_{s}^{\prime}-0.6239}-0.0017\right) d$

\section{Case study}

\subsection{Experimental design}

The experimental surveys were performed at Roma-Urbe Airport in Rome, Italy, using a vehicle of the Fire Department under load conditions comparable to those of the critical aircraft flying in this airport. The experiments were designed to verify the effectiveness of the tire-soil interaction model. The effects of the load exerted by the main gear on the CGAs during overrunning were simulated. Rutting and mechanical properties of the material involved in the overrun processes of the vehicle were measured. 3 Tests were carried out at different initial speeds of overrunning up to the stop of the vehicle. The collected data were implemented into the above mentioned predictive model and compared to the observed rutting.

\subsection{Test vehicle}

The vehicle of the Fire Department is a $39.24-\mathrm{kN}$ (4.0-ton) full load Mercedes-Benz Sprinter CHINETTI RIV 1200 as shown in Fig. 5. The load is equally distributed on the front and rear axles and it is assumed to be uniform for the single tire. Therefore, the load $F_{t}$ on the tire is $9.81 \mathrm{kN}(2204.58 \mathrm{lb})$. 


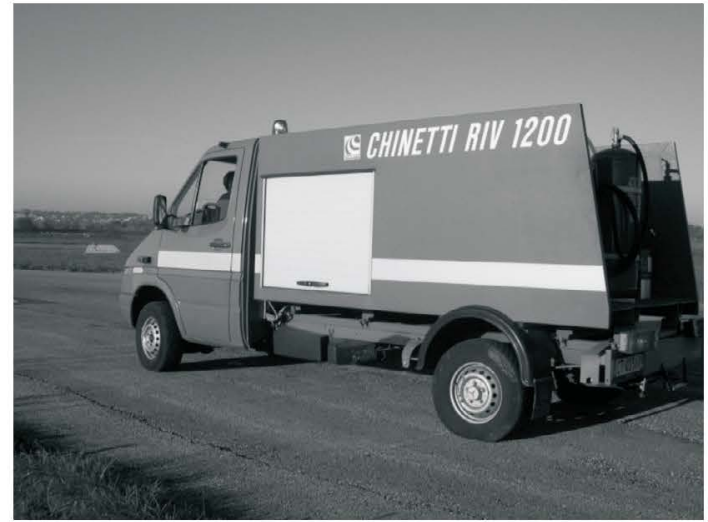

Fig. 5. Mercedes-Benz Sprinter CHINETTI RIV 1200 used for the overrunning simulation tests.

\subsection{Tire}

The tire used was a Continental Vanco-2 225/70R15 C 112/110 $\mathrm{R}$ at $344.74 \mathrm{kPa}(50 \mathrm{psi})$ of pressure $p$. Table 1 lists the tire characteristics required to be implemented into the model.

The tire is characterized by an unloaded overall diameter $d$ of $0.6959 \mathrm{~m}$ (27.39 in.) and a section width $b$ of $0.2235 \mathrm{~m}$ (8.80 in.). Section height $h_{t}$ and deflection $\delta_{t}$ are, respectively, $0.1575 \mathrm{~m}$ (6.20 in.) and $0.0551 \mathrm{~m}(2.17 \mathrm{in}$.).

\subsection{Test procedure}

The same general procedure was followed in each test to simulate the aircraft overrunning according to the proposed method. In particular, the vehicle accelerated to the target velocity up to the outer edge of the runway and the trajectory was aimed to follow a straight line. Moreover, the transmission of the vehicle was not in gear, and any braking maneuver was avoided.

3 Tests were carried out at different initial speeds of overrunning: $13.89 \mathrm{~m} / \mathrm{s} \quad(45.56 \mathrm{ft} / \mathrm{s}) \quad(27 \mathrm{knots}), \quad 16.67 \mathrm{~m} / \mathrm{s} \quad(54.68 \mathrm{ft} / \mathrm{s})$ ( $32.40 \mathrm{knots})$, and $19.44 \mathrm{~m} / \mathrm{s}(63.76 \mathrm{ft} / \mathrm{s})(37.79 \mathrm{knots})$; the test with a lower velocity was used for the calibration of the measurement procedures. At the end of each test, the vehicle stopping distance was measured: such distances were, respectively, $43.2 \mathrm{~m}$ $(141.73 \mathrm{ft})$ for the calibration test, $118 \mathrm{~m}(387.14 \mathrm{ft})$ and $150 \mathrm{~m}$ (492.13 ft) for tests 2 and 3.

Rut depths and profiles were measured along the overrunning trajectories by the following procedure. A thin metal sheet with pa- per taped to it was inserted into the rut section every $10 \mathrm{~m}$ $(32.81 \mathrm{ft}$ ). The paper was marked with a pen, outlining the upper shape of the rut with respect to the undisturbed surface at its side, as shown by Fig. $6 \mathbf{a}-\mathbf{c}$.

Such collected profiles were digitalized to assess the depth of the equivalent rectangular rut, arising from the equality between the detected rut surface (Fig. 7a) and the equivalent rectangular area (Fig. 7b), being equal the length of the tire footprint. Moreover, the mechanical properties of the soil were defined by $C B R$ tests and by using LFWD in correspondence to the collected rut sections.

\subsection{Grain size, plasticity, and mechanical properties of soils}

Both the grain size characterization tests and the Atterberg limits on the sampled material were carried out. Table 2 shows grading and plasticity of the soil. According to the HRB-AASHTO classification the soil is classified as "A-4 silty soil", as the value of Plastic Index PI was found to be $5.1 \%$, by the difference between the Liquid Limit $L_{L}(35.7 \%)$ and the Plastic Limit $P_{L}(30.6 \%)$.

With the aim to define the overall mechanical properties of the soil, 3 CBR tests were carried out according to [28]: the first test was carried out at $31 \%$ of water content by weight, under environmental moisture conditions. Other analyses were developed at $15 \%$ of moisture content by weight and measured, respectively, after 4 days of imbibition and at the end of the sample swelling. Low values (few percentage units) of $C B R$ indexes were found for those three tests, respectively equal to $3.0 \%, 16.1 \%$, and $15.5 \%$.

Analogously, LFWD was used in correspondence to the rut profiles for determining, section by section, the variability of the soil mechanical characteristics along the trajectory of overrunning. Fig. 8 shows the $C B R$ indexes obtained by the correlation with the LFWD measurements (U.S. Department of the Air Force, 2008 ), providing different values as much as the number of collected sections.

\section{Results}

\subsection{Experimental rut depths and estimated soil strength parameters}

Fig. 9 shows the experimental rut depth versus the stopping distance required for arresting the vehicle in safety. In general, greater levels of rutting were measured in case of higher speeds of overrunning, as expected.

Table 1

Continental Vanco-2 225/70R15 C 112/110 R tire characteristics at $344.74 \mathrm{kPa}$ (50 psi).

\begin{tabular}{|c|c|c|c|c|c|c|c|c|c|c|c|}
\hline \multicolumn{2}{|l|}{ Load } & \multicolumn{2}{|c|}{ Footprint width } & \multicolumn{2}{|c|}{ Tire section height } & \multicolumn{2}{|c|}{ Diameter } & \multicolumn{2}{|c|}{ Tire deflection } & \multicolumn{2}{|c|}{ Inflation pressure } \\
\hline [lb] & {$[\mathrm{N}]$} & [in.] & {$[\mathrm{m}]$} & [in.] & {$[\mathrm{m}]$} & [in.] & {$[\mathrm{m}]$} & [in.] & {$[\mathrm{m}]$} & [psi] & {$[\mathrm{Pa}]$} \\
\hline 2204.58 & 9810 & 8.80 & 0.2235 & 6.20 & 0.1575 & 27.39 & 0.6959 & 2.17 & 0.0551 & 50 & 344740 \\
\hline
\end{tabular}

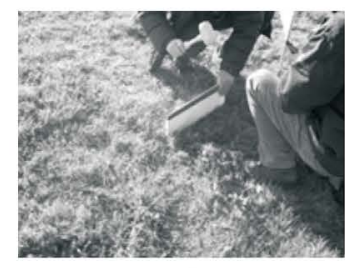

a

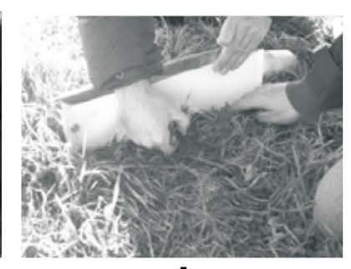

b

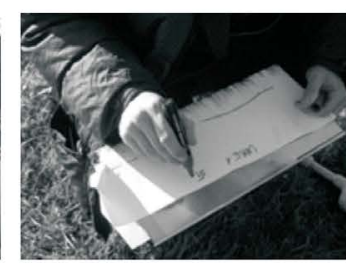

C

Fig. 6. Rut profile measurement. 


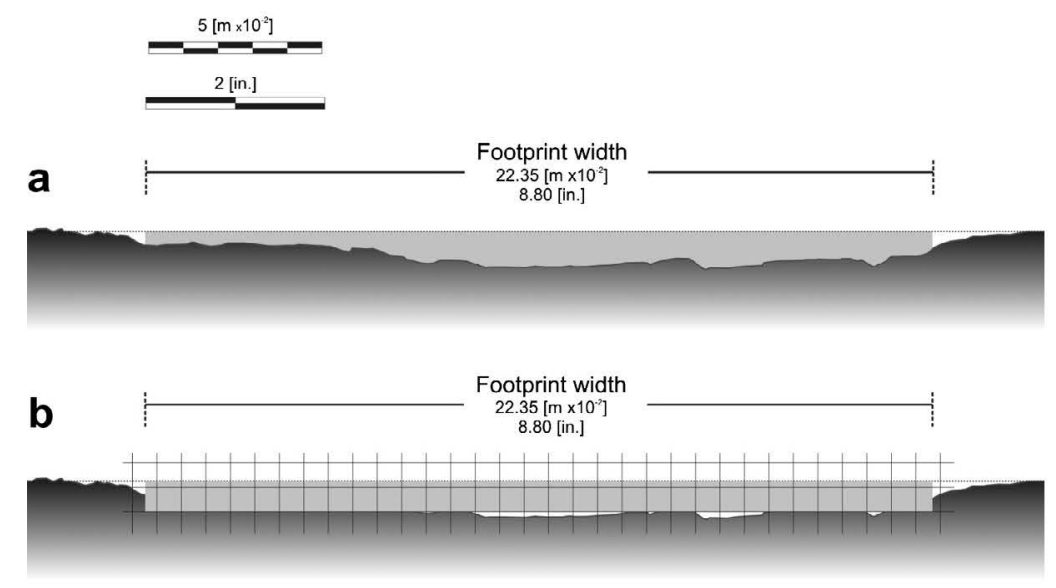

Fig. 7. Rut depth assessment, (a) detected rut depth, (b) equivalent rut depth.

Table 2

Grain size distribution and plasticity characteristics of the sunk soil.

\begin{tabular}{ll}
\hline Tested characteristics & CGA soil [\%] \\
\hline Granulometric analysis & \\
$\mathrm{P}_{4.75}$ & 99.99 \\
$\mathrm{P}_{2}$ & 99.41 \\
$\mathrm{P}_{1.18}$ & 99.23 \\
$\mathrm{P}_{0.425}$ & 98.17 \\
$\mathrm{P}_{0.180}$ & 84.83 \\
$\mathrm{P}_{0.075}$ & 64.85 \\
Atterberg limits & \\
$\mathrm{L}_{\mathrm{L}}$ & 35.7 \\
$\mathrm{P}_{\mathrm{L}}$ & 30.6 \\
$\mathrm{P}_{\mathrm{I}}$ & 5.1 \\
AASHTO group & A4 (silty soil) \\
\hline
\end{tabular}

Concerning test 2 , a steep decreasing of rut depth is observed within the first $10 \mathrm{~m}(32.81 \mathrm{ft})$ from $0.01 \mathrm{~m}(0.3937 \mathrm{in}$.) to $0.005 \mathrm{~m}$ (0.1969 in.) deep. The overall sinking profile decreases in the stopping distance range $10-50 \mathrm{~m}(32.81-164.04 \mathrm{ft})$, respectively from $0.005 \mathrm{~m}(0.1969 \mathrm{in}$.) to $0.004 \mathrm{~m}(0.1575 \mathrm{in}$.) deep, and then increases along the next $30 \mathrm{~m}(98.43 \mathrm{ft})$ up to $0.008 \mathrm{~m}$ (0.3150 in.) deep. Subsequently, a steep lowering of sinking is

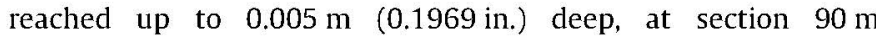
$(295.28 \mathrm{ft})$. Beyond this point, the depth moderately decreases up to a minimum peak of $0.004 \mathrm{~m}(0.1575 \mathrm{in}$.) deep, at section $110 \mathrm{~m}(360.89 \mathrm{ft})$.

Concerning test 3 , the rut profile remains fairly levelled within the first $20 \mathrm{~m}(65.62 \mathrm{ft})$, increases briefly up to the highest reached value of $0.0105 \mathrm{~m}(0.4134 \mathrm{in}$.) deep, at section $30 \mathrm{~m}(98.43 \mathrm{ft})$, steeply decreases up to $0.008 \mathrm{~m}$ (0.315 in.) deep, and then remains fairly constant up to $70 \mathrm{~m}(229.66 \mathrm{ft})$ of stopping distance, with a small rise from $0.0075 \mathrm{~m}$ (0.2953 in.) to $0.009 \mathrm{~m}$ (0.3543 in.) deep in the range $50-70 \mathrm{~m}(164.04-229.66 \mathrm{ft})$. Beyond this range, the sinking profile steeply decreases until the minimum peak of $0.004 \mathrm{~m}$ (0.1575 in.) deep, at section $90 \mathrm{~m}$ (295.28 ft), quickly increases up to $0.01 \mathrm{~m}(0.3937 \mathrm{in}$.) deep, and then fairly constantly decreases until $0.0055 \mathrm{~m}$ (0.2165 in.) deep, at section $140 \mathrm{~m}$ $(459.32 \mathrm{ft})$

In both tests, increasing trends of rutting are shown in the last $10 \mathrm{~m}$ ( $32.81 \mathrm{ft})$, whereas the forward speed approaches to zero.

As mentioned above, soil strength parameters deeply affect rutting in unpaved surfaces. In that respect, LFWD was used to assess the soil elastic modulus, according to the Boussinesq solution as follows:

$E_{L F W D}=\frac{k\left(1-v^{2}\right) \sigma R}{\delta_{c}}$
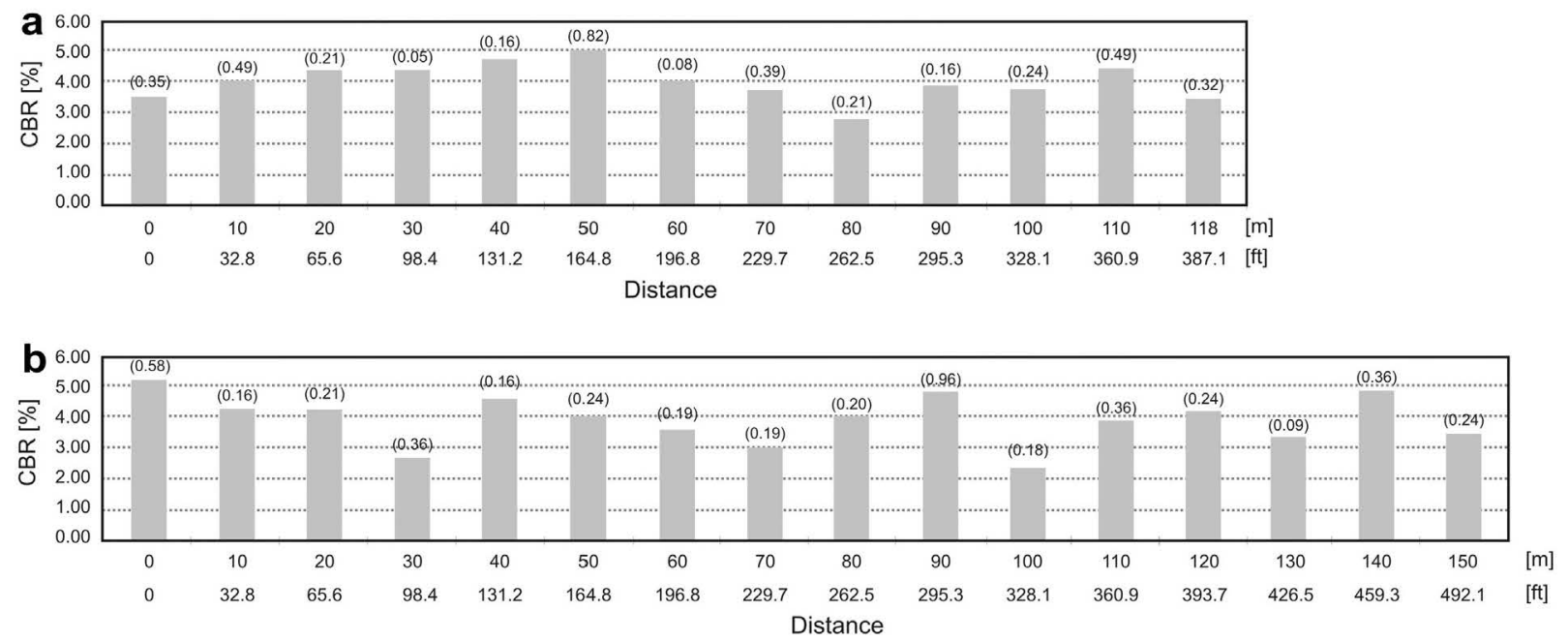

Fig. 8. CBR indexes arising from the correlation with LFWD measurements (in brackets, the Standard Deviation), (a) "test 2 " $16.67 \mathrm{~m} / \mathrm{s}$ ( $54.68 \mathrm{ft} / \mathrm{s}$ ) ( $32.40 \mathrm{knots}$ ) initial speed of overrunning, (b) "test 3" $19.44 \mathrm{~m} / \mathrm{s}(63.76 \mathrm{ft} / \mathrm{s})(37.79 \mathrm{knots})$. 


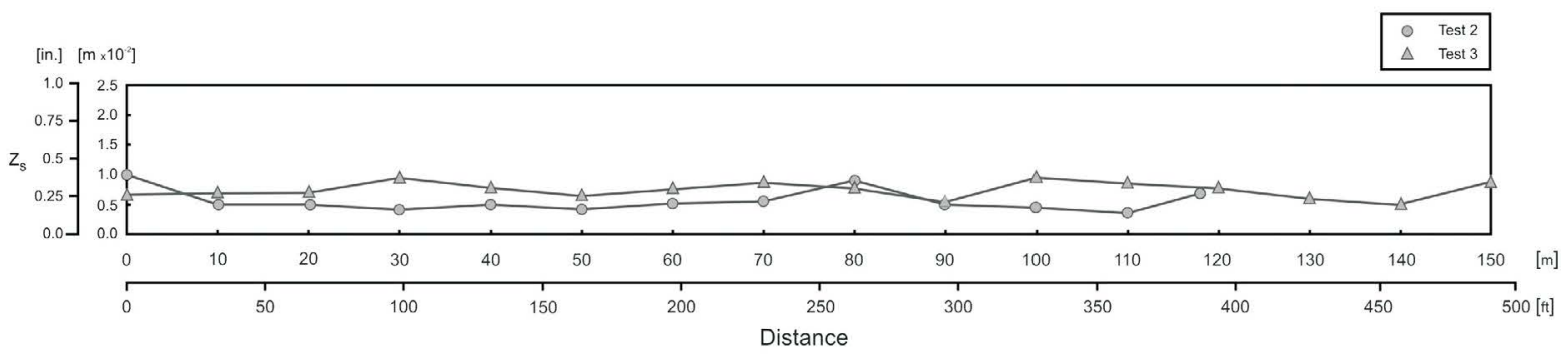

Fig. 9. Experimental rut depth versus stopping distance.
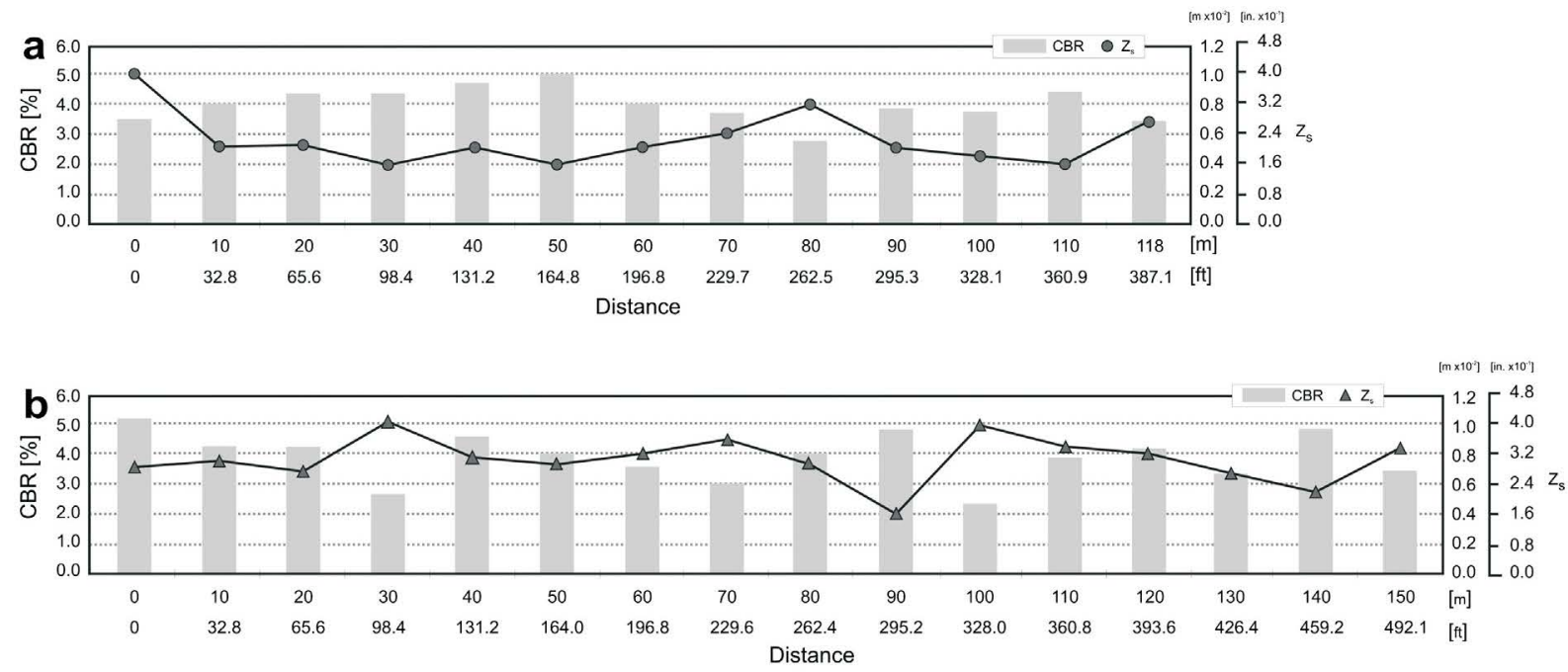

Fig. 10. Experimental rut depths versus CBR indexes, (a) "test 2" $16.67 \mathrm{~m} / \mathrm{s}(54.68 \mathrm{ft} / \mathrm{s})(32.40 \mathrm{knots})$ initial speed of overrunning, (b) "test 3 " $19.44 \mathrm{~m} / \mathrm{s}$ (63.76 ft/s) (37.79 knots).

where $E_{L F W D}$ is the elastic modulus in $\mathrm{MPa}, k$ equals $\pi / 2$ or 2 for rigid and flexible LFWD plates, respectively, $\delta_{c}$ is the center deflection in $\mu \mathrm{m}, v$ is the Poisson's ratio, and $\sigma$ is the applied stress at a distance $R$.

According to the U.S. Department of the Air Force (2008), the following equation has been used to determine $C B R$, from the calculated elastic modulus $E$, expressed in \% and psi, respectively:

$$
C B R=\frac{E}{1500}
$$

Fig. 10 shows the comparison between measured rut depths and corresponding CBR indexes of each section in both tests 2 (Fig. 10a) and 3 (Fig, 10b).

In Fig. 10a the maximum levels of rutting are shown at $0 \mathrm{~m}$ (" $0 \mathrm{~m}$ section"), $80 \mathrm{~m}(262.47 \mathrm{ft})$, and $118 \mathrm{~m}$ ( $387.14 \mathrm{ft})$ sections, equal to $0.01 \mathrm{~m}$ (0.3937 in.), $0.008 \mathrm{~m}$ (0.3150 in.), and $0.007 \mathrm{~m}$ (0.2756 in.) deep, respectively. Such depths match the lowest values of inferred $C B R$, respectively, $3.51 \%, 2.80 \%$, and $3.47 \%$. Similarly, sinkings amount to the lowest collected values in case of $C B R \geqslant 4 \%$, ranging from $0.005 \mathrm{~m}$ (0.1969 in.) to $0.004 \mathrm{~m}$ (0.1575 in.) deep.

Results of test 3 are shown in Fig. 10b. Greater levels of sinking were obtained at $30 \mathrm{~m}(98.43 \mathrm{ft}), 70 \mathrm{~m}(229.66 \mathrm{ft})$, and $100 \mathrm{~m}$ ( $328.08 \mathrm{ft}$ ) sections, with respective values equal to $0.0105 \mathrm{~m}$ (0.4134 in.), $0.009 \mathrm{~m}$ (0.3543 in.), and $0.010 \mathrm{~m}$ (0.3937 in.) deep. The corresponding $C B R$ indexes equal $2.63 \%, 3.09 \%$, and $2.45 \%$, respectively, and were the lowest values measured along the overrunning trajectory. Analogously, the range of values varies from $0.004 \mathrm{~m}(0.1575 \mathrm{in}$.) up to $0.007 \mathrm{~m}(0.2756 \mathrm{in}$.) deep in case of $C B R \geqslant 4.55 \%$, corresponding to the minimum levels of rut depth.

\subsection{Tire-soil model application}

Data concerning the velocity of overrunning, tire characteristics, and loads applied were implemented into the numerical model according to the above mentioned information. Moreover, Eq. (1) was used to make the collected strength parameters suitable for the application of the numerical model. According to Table 2, the soil properties can be compared to those of a low plastic clay, with coefficients $a$ and $b$ equal, respectively, to 0.1266 and 0.6986 .

The model was firstly developed using a constant value of $C B R$ equal to $3 \%$ all over the run, as resulted from laboratory tests under typical moisture conditions of the soil. Fig. 11 shows the experimental rut depths compared to the predicted rut depths in both tests.

As it can be seen in Fig. 11a, the model initially underestimates the observed depths until about $8.5 \mathrm{~m}$ (27.89 ft) of distance, with the maximum difference of $0.0042 \mathrm{~m}(0.1654 \mathrm{in}$.) in section $0 \mathrm{~m}$. Beyond this point, the model slightly overestimates the experimental rut depths until $58.7 \mathrm{~m}$ (192.59 ft) of distance, where the observed sinking increases more rapidly than the predicted depths, reaches the higher difference of about $0.0035 \mathrm{~m}$ ( $0.1378 \mathrm{in}$.), and further decreases until approximately $90 \mathrm{~m}$ $(295.28 \mathrm{ft}$ ) of distance. An overlap is then observed from section $90 \mathrm{~m}$ to $110 \mathrm{~m}(295.28-360.89 \mathrm{ft})$, where the rut depth remains fairly levelled across the range $0.0042-0.0045 \mathrm{~m}$ (0.16540.1772 in.) deep. The predicted data never exhibit a tendency of increasing rut depth, with the exception of the last $9 \mathrm{~m}$ $(29.53 \mathrm{ft})$. Within such distance, the predictive model underestimates rutting up to the final section, where it steeply exceeds the observed rut depth of $0.0057 \mathrm{~m}$ (0.2244 in.). 

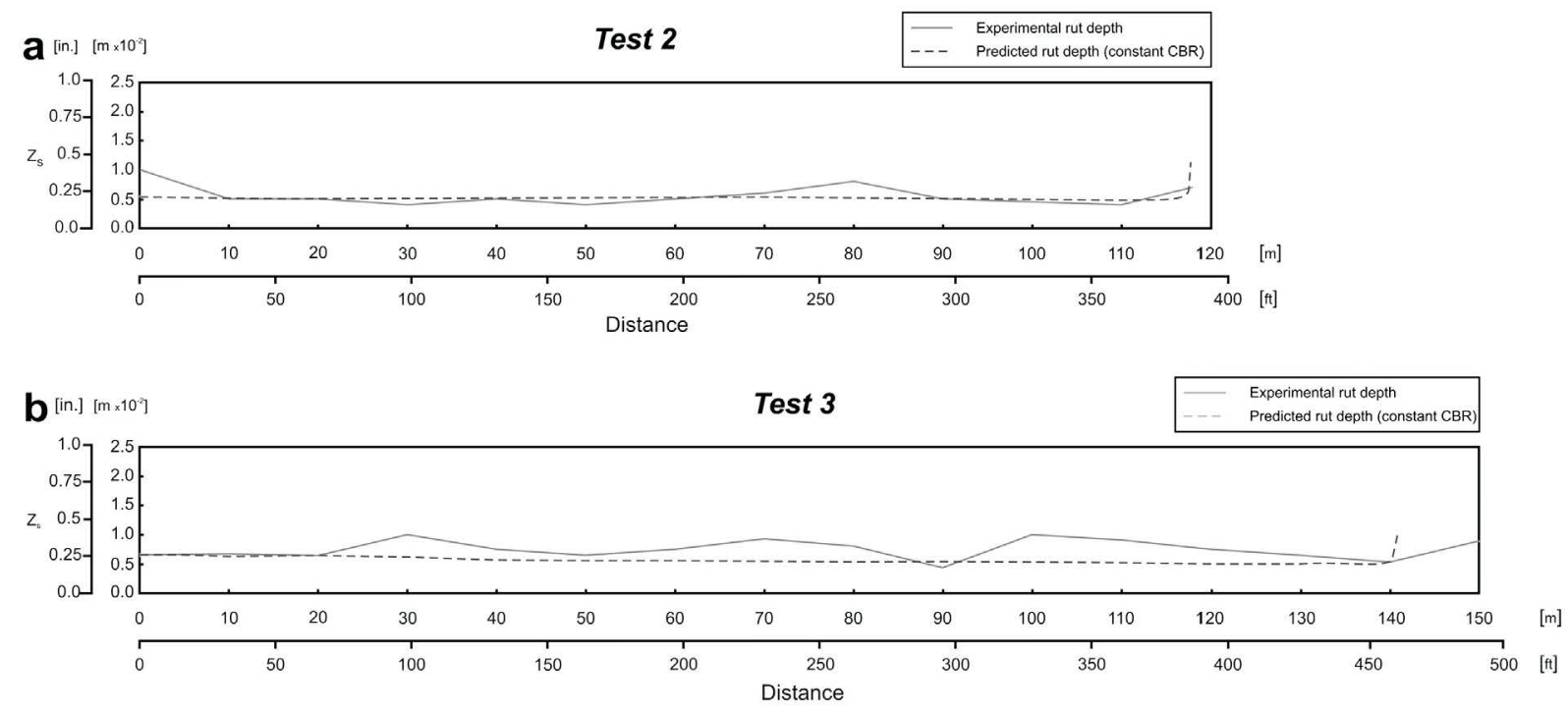

Fig. 11. Experimental rut depths versus predicted rut depths using CBR constant values, (a) "test 2 " $16.67 \mathrm{~m} / \mathrm{s}$ ( $54.68 \mathrm{ft} / \mathrm{s}$ ) (32.40 knots) initial speed of overrunning, (b) "test 3" $19.44 \mathrm{~m} / \mathrm{s}(63.76 \mathrm{ft} / \mathrm{s})(37.79 \mathrm{knots})$.
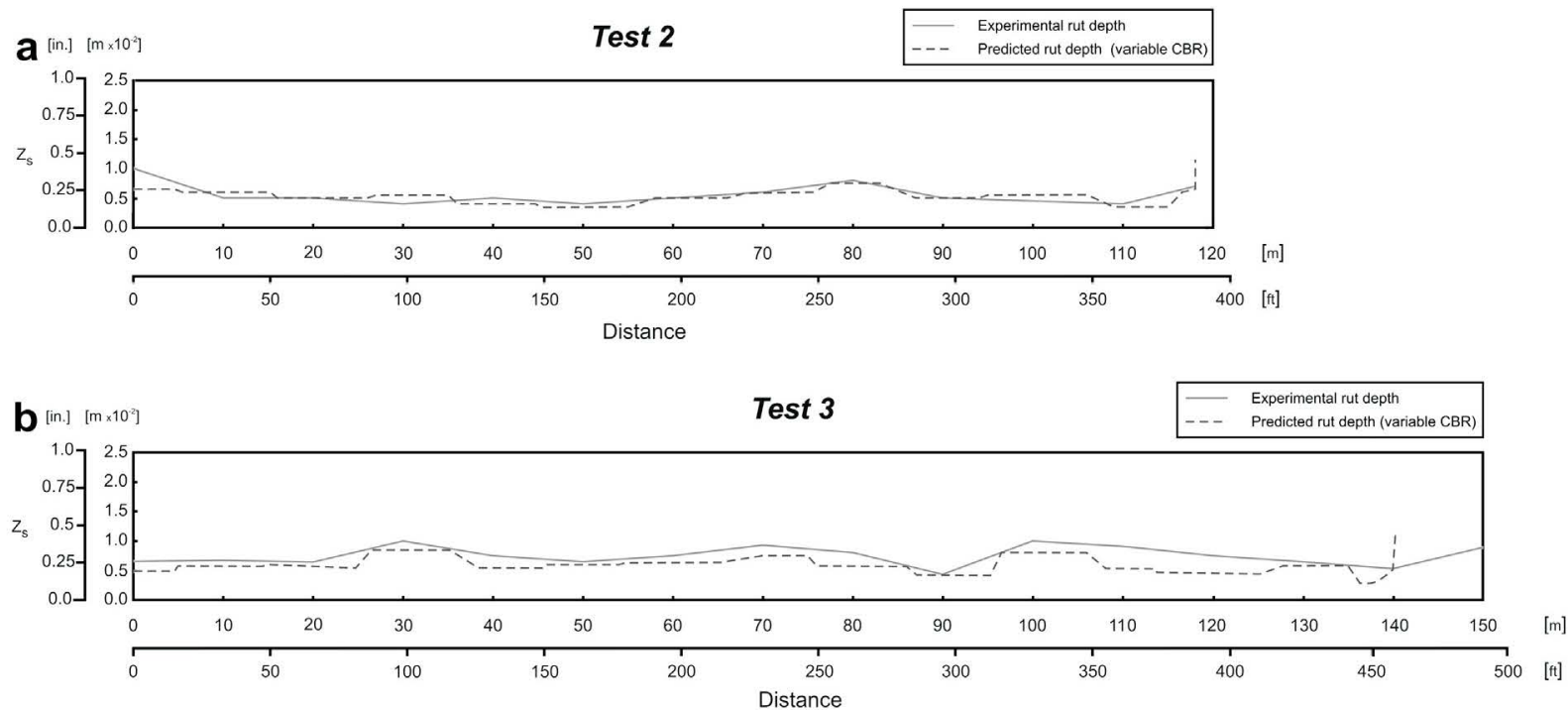

Fig. 12. Experimental rut depths versus predicted rut depths using CBR discretized values, (a) "test 2" $16.67 \mathrm{~m} / \mathrm{s}$ (54.68 ft/s) (32.40 knots) initial speed of overrunning, (b) "test 3" $19.44 \mathrm{~m} / \mathrm{s}(63.76 \mathrm{ft} / \mathrm{s})(37.79 \mathrm{knots})$.

Fig. 11b compares the observed rut depth values and those predicted in test 3. It is shown that the model generally underestimates the experimental data except in the range $85-92.5 \mathrm{~m}$ $(278.87-303.48 \mathrm{ft})$. An overlap can be initially observed from section $0 \mathrm{~m}$ to $20 \mathrm{~m}(0-65.62 \mathrm{ft})$ where rutting remains fairly levelled around the value of $0.007 \mathrm{~m}$ (0.2756 in.) deep. Beyond this range, a mismatch between the curves can be noted in the range $20-85 \mathrm{~m}$ $(65.62-278.87 \mathrm{ft})$, reaching two maximum peaks in sections $30 \mathrm{~m}$ $(98.43 \mathrm{ft})$ and $70 \mathrm{~m}(229.66 \mathrm{ft})$, and remaining nearly constant at around $0.0015 \mathrm{~m}$ (0.0591 in.) deep in the range $40-60 \mathrm{~m}$ (131.23-196.85 ft) of distance. Rut depth is then overestimated with a maximum difference of about $0.0017 \mathrm{~m}(0.0669 \mathrm{in}$.) at section $90 \mathrm{~m}(295.28 \mathrm{ft})$. Subsequently, the values of observed rutting return higher than those predicted by the model, reaching the largest difference of about $0.0045 \mathrm{~m}(0.1772 \mathrm{in}$.) in the whole test 3 . In the final section, the predictive model exceeds the experimental value of $0.0086 \mathrm{~m}$ (0.3386 in.).
In the second step, the numerical model was implemented using variable soil mechanical characteristics, section by section, inferred from the LFWD measurements. Fig. 12 shows the comparison between the observed and the predicted rut depths in both tests.

Fig. 12a shows an overall good agreement between the curve from the integrated model and the curve from the observed data, thereby showing an improvement of the first application of the model (Fig. 11a). For instance, the largest differences decrease from $0.0042 \mathrm{~m}(0.1654 \mathrm{in}$.) to $0.0033 \mathrm{~m}(0.1181 \mathrm{in}$.), and from $0.0033 \mathrm{~m}$ (0.1181 in.) to $0.0012 \mathrm{~m}(0.0472 \mathrm{in}$.$) , in sections 0 \mathrm{~m}$ and $80 \mathrm{~m}$ (261.47 ft), respectively.

Analogously, Fig. 12b shows a greater reliability of the integrated numerical model compared to the results shown in Fig. 11b. The larger differences between predicted and observed values decrease more than $100 \%$ : from $0.0038 \mathrm{~m}$ ( 0.1496 in.) to $0.0015 \mathrm{~m}$ (0.0591 in.) in section $30 \mathrm{~m}(98.43 \mathrm{ft})$, from $0.0029 \mathrm{~m}$ 
(0.1142 in.) to about $0.0014 \mathrm{~m}(0.0551 \mathrm{in}$.) in section $70 \mathrm{~m}$ (229.66 ft), and from $0.0045 \mathrm{~m}(0.1772 \mathrm{in}$.) to $0.0019 \mathrm{~m}$ (0.0748 in.) in section $100 \mathrm{~m}(328.08 \mathrm{ft})$.

\section{Discussion}

The proposed method for the prediction of rutting induced by aircraft overrunning in natural CGA soils has proved to be much more efficient and effective than any other traditional one. The most important improvement concerns the use of the LFWD to characterize better and rapidly, section by section, the soil strength parameters along the trajectory of overrunning.

High consistency exists between the observed rut depths and the values of $C B R$ from LFWD measurements. As expected, greater rutting was observed where the soil was characterized by lower $C B R$ indexes and, conversely, better mechanical properties (higher $C B R$ indexes) led to lower observed rut depths. Moreover, an overall consistency among experimental rut depths $Z_{s}$ versus $C B R$ indexes of two consecutive sections was shown, with the exception of ranges $20-40 \mathrm{~m}(65.62-131.23 \mathrm{ft})$ and $90-100 \mathrm{~m}(295.28-$ $328.08 \mathrm{ft}$ ) in test 2 (Fig. 10a), and ranges $10-20 \mathrm{~m}$ (32.81-65.62 $\mathrm{ft}), \quad 40-50 \mathrm{~m} \quad(131.23-164.04 \mathrm{ft})$, and $120-130 \mathrm{~m}$ (393.7$426.51 \mathrm{ft}$ ) in test 3 (Fig. 10b). In both cases, the variability was negligible.

Results from the integrated method demonstrate that such procedure can predict rutting values much closer to those observed. Fig, $13 \mathrm{a}$ and $\mathrm{b}$ show the relative residuals, calculated as the differ- ence between the observed and the predicted rutting, both through the traditional and the integrated model, and their relative incidence in terms of percent, compared to the corresponding values of observed rutting. Generally, it is shown that such residuals are lower when the integrated method is used.

In test 2 (Fig. 13a), the highest relative residual equals to $+0.0042 \mathrm{~m}(0.1654 \mathrm{in}$.) for the traditional model, and $+0.0033 \mathrm{~m}$ ( 0.1299 in.) for the integrated model, by excluding the last section, where both the models deeply overestimate the experimental data. Analogously, the percentage difference between the maximum and minimum level of incidence of residuals decreases by using the integrated method, being in the range $+34.4 \%$ to $-36.5 \%$ for the traditional model, and $+32.7 \%$ to $-28.3 \%$ for the integrated one. Data show that the largest values of incidence of residuals related to the traditional method are generally much higher than those arising from the integrated method: in particular, within the stopping distance range $67-98 \mathrm{~m}$ (219.82-321.52 ft), such values are largely more than halved using the integrated method. The analysis of residuals for test 2 demonstrates that generally the integrated model fits the measured data better than the traditional method, with the exception of some few cases, where residuals are slightly lower for the traditional method, and except for slow speeds, where the differences between the incidences of residuals are more evident.

From the residuals plot of test 3 (Fig. 13b), it is shown that, by excluding the last section, the maximum relative residual for the traditional method is greater than that arising from the integrated method, being respectively $+0.0045 \mathrm{~m}(0.1772$ in.) and $+0.0037 \mathrm{~m}$

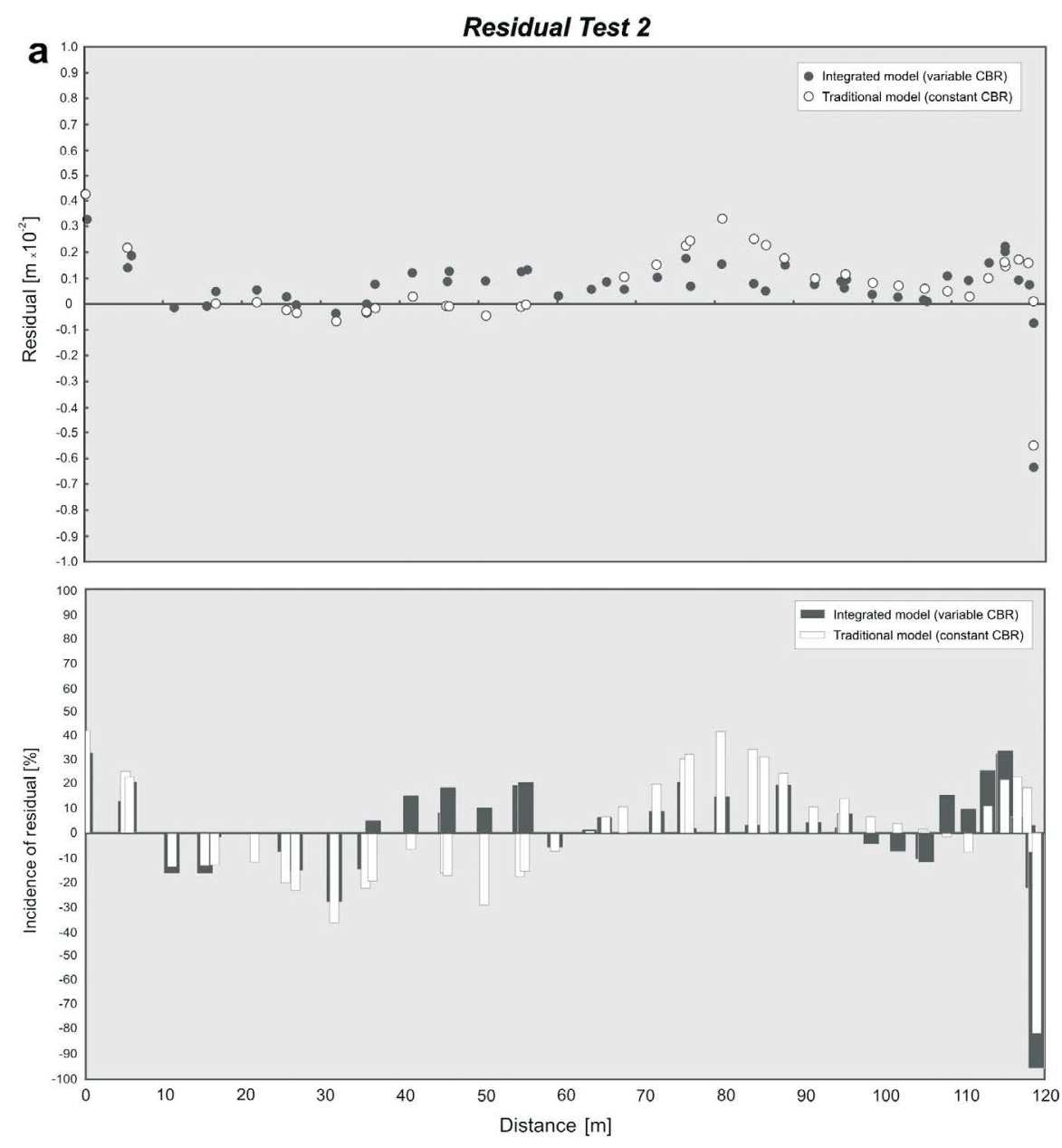

Fig. 13. Positive and negative residuals arising from the application of the two predictive models versus the incidence of residuals, (a) "test 2 " $16.67 \mathrm{~m} / \mathrm{s}$ ( $54.68 \mathrm{ft} / \mathrm{s}$ ) (32.40 knots) initial speed of overrunning, (b) "test 3" $19.44 \mathrm{~m} / \mathrm{s}(63.76 \mathrm{ft} / \mathrm{s})(37.79 \mathrm{knots})$. 

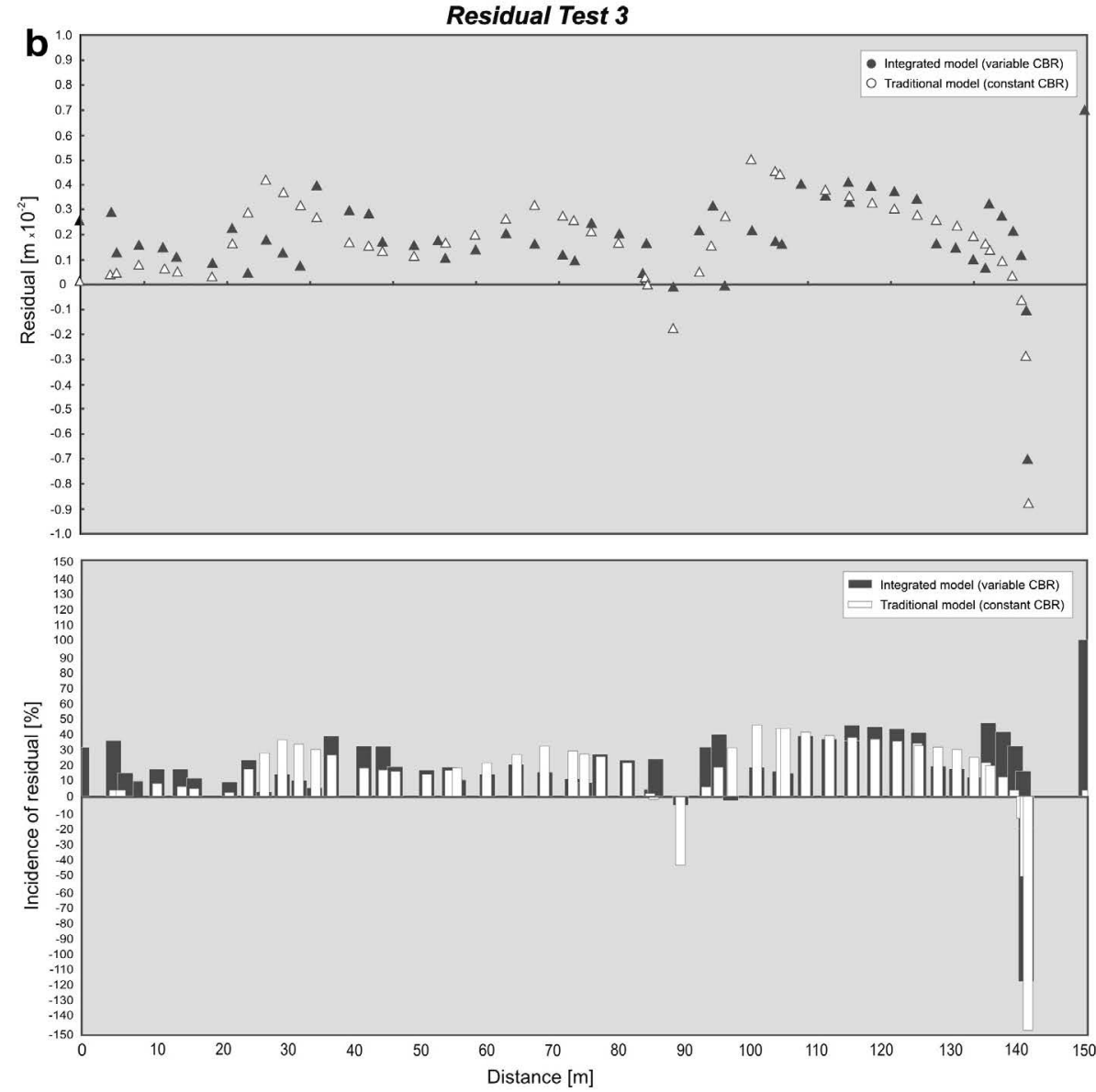

Fig. 13 (continued)
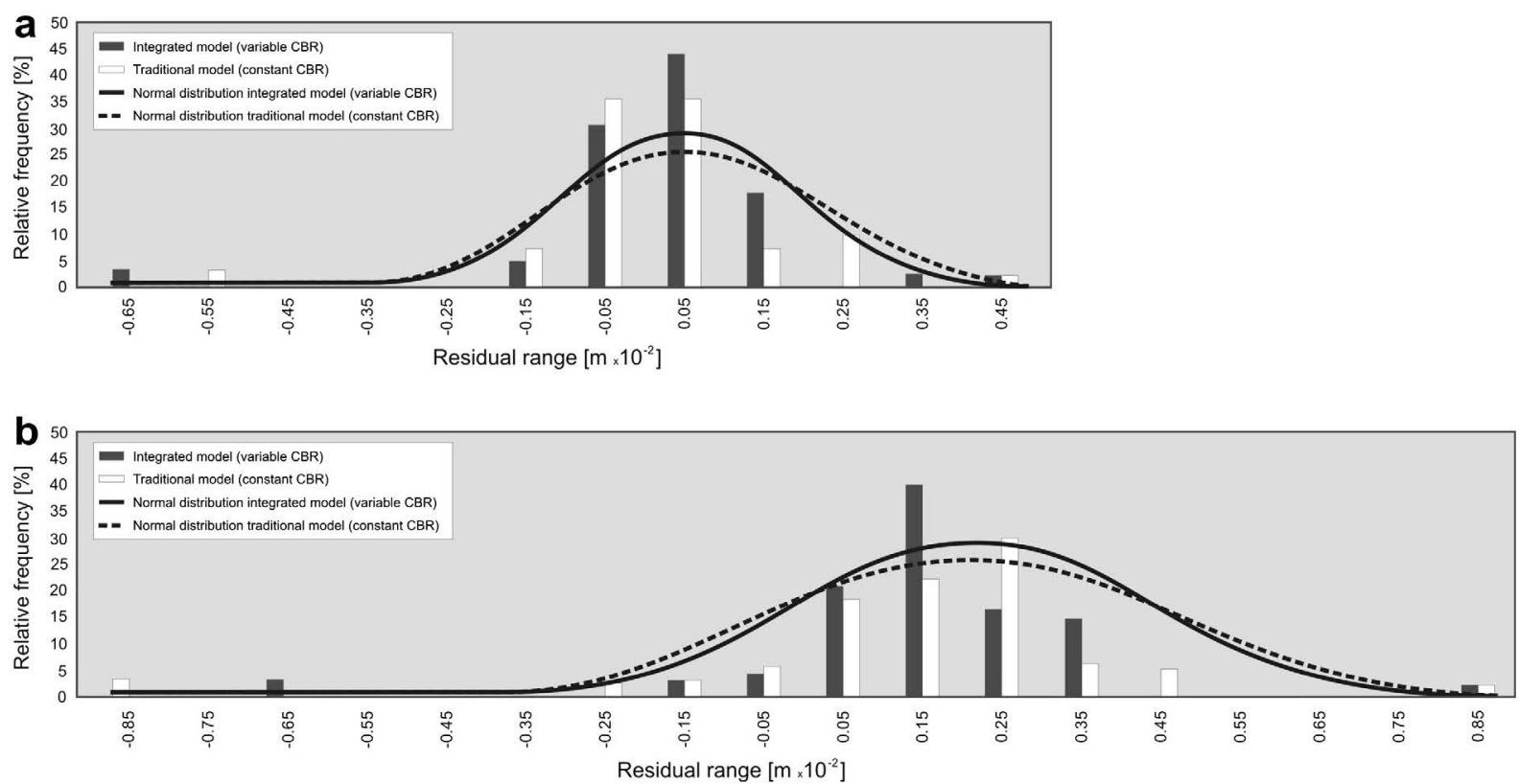

Fig. 14. Density distribution of residuals, (a) "test 2 " $16.67 \mathrm{~m} / \mathrm{s}$ (54.68 ft/s) (32.40 knots) initial speed of overrunning, (b) "test 3" $19.44 \mathrm{~m} / \mathrm{s}$ (63.76 ft/s) (37.79 knots).

( 0.1457 in.). Moreover, the analysis of the incidences of residuals shows that the maximum and minimum percentage values range between $+45.3 \%$ and $-43.0 \%$ for the traditional method, and be- tween $+44.9 \%$ and $-5.6 \%$ for the integrated method. The traditional model fits the measured data better than the integrated one at the highest and lowest speeds. Within the stopping distance range 25- 
$135 \mathrm{~m}(82.02-442.91 \mathrm{ft})$, the incidences of residuals from the integrated method are generally lower than those registered with the traditional method. Moreover, when these incidences exceed the ones resulting from the traditional method (e.g., in the stopping distance range $115-125 \mathrm{~m}$ (377.3-410.1 ft)) slight differences can be observed.

Fig. 14a and b show that residuals are distributed according to a Gaussian distribution for both the traditional and the integrated model, although a slight asymmetry in the distribution of data can be found.

In Fig. 14a it is shown as the normal distribution of residuals related to the use of the integrated model is better shaped around the mean $\mu$ than that determined by the use of the traditional model. In particular, the analysis of the distribution parameters concerning test 2 , indicates that the mean $\mu$ decreases from $0.0003 \mathrm{~m}$ $(0.0118 \mathrm{in}$.) to $0.0002 \mathrm{~m}(0.0079 \mathrm{in}$.) by using the integrated method. Similarly, the lowering of the standard deviation $\sigma$ from $0.0016 \mathrm{~m}(0.0630 \mathrm{in}$.) to $0.0014 \mathrm{~m}(0.0551 \mathrm{in}$.) demonstrates a lower dispersion of the residuals around the mean $\mu$ in case of prediction through variable CBR indexes.

Analogously, the comparison of the normal distributions of residuals by using such two models (Fig. 14b) confirms that the integrated model fits the measured data better than the traditional one. In fact, although the mean $\mu$ is slightly higher for the integrated model, being $0.0016 \mathrm{~m}$ (0.0630 in.) compared with $0.0017 \mathrm{~m}(0.0669 \mathrm{in}$.) from the traditional model, a lowering of the standard deviation $\sigma$ from $0.0022 \mathrm{~m}(0.0866 \mathrm{in}$.) to $0.0018 \mathrm{~m}$ (0.0709 in.) can be observed.

\section{Conclusion}

The paper proposes an integrated method for the prediction of rut depths in natural soils induced by aircraft overrunning and based on a numerical streamlined model. The model uses measurements from light falling weight deflectometer. Experimental tests have been carried out. Overrunning-velocities, tire characteristics, and loads applied, all related to a test vehicle were known. Once the overrunning of the experimental vehicle was stopped, rut depths have been measured. To assess the reliability of the model, results have been compared to the sinkings observed along the trajectory of the overrunning vehicle. Further comparisons have been carried out by using constant values of $C B R$, assessed through laboratory standard procedures.

Results demonstrate that a more detailed description of the soil strength properties plays a deeply important role in the prediction of rutting. By using discretized values of $C B R$, section by section, the experimental data have been fitted much more adequately through the integrated method, and negligible errors have been observed. On the basis of such promising results, the proposed procedure has proved to be much more time-efficient and costeffective than any other traditional one.

\section{Acknowledgement}

The authors express their thanks to Mr. Spartaco Cera, University Roma Tre, for providing valuable help and supporting in this study.

\section{References}

American Society for Testing and Materials (ASTM), 2009. Standard Test Method for CBR (California Bearing Ratio) of Soils in Place. Annual Book of ASTM Standards 2009, D4429 - 09a.

Bade, E., 1969. Soft-ground arresting of civil aircraft-influence of gravel depth and tyre inflation pressure. UK Ministry of Defence Technical Report 69001, Hampshire, England. Royal Aircraft Establishment Farnborough.
Barnes, J.R., 1974. Development of a model technique for investigating the performance of soft-ground arresters for aircraft. UK Ministry of Defence Technical Report 71231, Hampshire, England. Procurement Executive, Royal Aircraft Establishment Farnborough.

Beaty, I., 1975. An investigation into the rolling resistance if a full size meteor wheel in dry Leighton Buzzard sand using the heavy load friction vehicle. UK Ministry of Defence DRIC-BR-49447, S\&T Memo 6-75, DA Mech, England. Procurement Executive.

Belobaba, P.P., Mehdi, B.A., William, S., 2012. Impacts of LCC growth on domestic traffic and fares at largest US airports. Journal of Air Transport Management 18, 21-25.

Benedetto, A, Tosti, F., Di Domenico, L., 2012. Elliptic model for prediction of deflections induced by a Light Falling Weight Deflectometer. Journal of Terramechanics $49(1), 1-12$.

Bennett, D.L., 2005. Engineered material arresting systems (EMAS) for aircraft overruns. U.S. FAA advisory circular AC 150/5220 - 22A, Washington, DC. U.S. Department of Transportation, Federal Aviation Administration.

Boeing Commercial Airplanes, 1992. Airplane characteristics for airport planning, 777. Boeing Document D6-58329, Boeing Commercial Airplane Company, Seattle, Washington.

Coutermarsh, B., 2007. Velocity effect of vehicle rolling resistance in sand. Journal of Terramechanics 44, 275-291.

Crenshaw, B.M., 1972. Aircraft landing gear dynamic loads induced by soil landing fields. Air Force Flight Dynamics Laboratory - Air Force Systems Command - Air Force Base, Wright-Patterson AFB, Ohio, vol. 1.

David, R.E., 1990. Location of commercial aircraft accidents/incidents relative to runways. FAA Report 90-1. Washington, DC. U.S. Department of Transportation, Federal Aviation Administration, Office of Safety Oversight.

Deloach, R., Marlowe, J.M., Yager, T.J., 2009. Uncertainty analysis for the evaluation of a passive runway arresting system. NASA Langley Research Center - ATK Space Systems, Hampton, Virginia.

Desai, A., Auad, M.L., Shen, H., Nutt, S.R., 2007. Hybrid composite phenolic foams. U.S. Government. In: Proceedings of Composites \& Polycon, Tampa, FL

Gibbesch, A., 2002. High-speed tyre-soil interaction of aircraft on soft runways. In: Proceedings of 14th International Conference of the International Society for Terrain-Vehicle Systems, Vicksburg, MS, USA.

Gwynne, G.M., 1975. Urea formaldehyde foamed plastic emergency arresters for civil aircraft. UK Ministry of Defence Technical Report 74002, Hampshire, England. Procurement Executive, Royal Aircraft Establishment Farnborough.

Hall, J., Ayres Jr., M., Wong, D., Appleyard, A., Eddowes, M., Shirazi, H., Speir, R., Pitfield, D., Caves, R., Selezneva, O., Puzin, T., 2008. Analys is of aircraft overruns and undershoots for runway safety areas. ACRP Report 08-3. Washington, DC. Transportation Research Board.

Heymsfield, E., Halsey, T.L., 2007. Sensitivity analysis of engineered material arrestor systems to aircraft and arrestor material characteristics. Transportation. Research Record 10, 110-117.

Ho, C.H., Romero, P., 2009. Investigation of existing engineered material arresting system at three U.S. Airports. In: Proceedings of 50th Annual Forum of Transportation Research Forum, Portland, Oregon, USA

Jiang, X., Ci, L., Chi, Y., Yan, J., 2010. TG-FTIR study on urea-formaldehyde resin residue during pyrolysis and combustion. Journal of Hazardous Materials 173 (1-3), 205-210.

Kavussi, A., Rafiei, K, Yasrobi, S., 2010. Evaluation of PFWD as potential quality control tool of pavement layers. Journal of Civil Engineering and Management $16(1), 123-129$

Kirkland, I.D.L., Caves, R.E., Humphreys, I.M., Pitfield, D.E., 2004. An improved methodology for assessing risk in aircraft operations at airports, applied to runway overruns. Safety Science 42 (10), 891-905.

Lang, C.M., 2004. Financial feasibility and equivalency of runway safety area improvements and engineered material arresting systems. FAA Order 5200.9, Washington, DC. U.S. Department of Transportation, Federal Aviation Administration

Lee, J.L.Y. Chen, D.H., Stokoe, K.H., Scullion, T., 2004. Evaluating potential for reflection cracking with rolling dynamic deflectometer. Transportation Research Record 1869, 16-24.

Liu, C.H., Wong, J.Y., 1996. Numerical simulations of tire-soil interaction based on critical state soil mechanics. Journal of Terramechanics 33 (5), 209-221.

Marisetty, S.C., Bailey, E.D., Micah Hale, W. Heymsfield, E.P., 2008. Development of a soft ground arrestor system. MBTC Final Report 2089, Fayetteville, AR. U.S. Department of Transportation, Research and Special Programs Administration.

O'Donnell, M.J., 2005. Engineered material arresting systems (EMAS) for aircraft overruns, U.S. FAA advisory circular AC 150/5220 - 22B, Washington, DC. U.S. Department of Transportation, Federal Aviation Administration.

PlaneCrashInfo.com Database. <http://planecrashinfo.com/database.htm> (retrieved 15 May 2012).

Randall, T.G., 1970. Preliminary feasibility study of the arresting of aircraft in a foamed plastic overrun area. Technical Memorandum Naval 213, Hampshire, England. Royal Aircraft Establishment Farnborough.

Richmond, L.D., Brueske, N.W., Debord, K.J., 1968. Aircraft dynamic loads from substandard landing sites, Part II, development of tire-soil mathematical model. AFFDL-TR-67-145, Part II. US Air Force Flight Dynamics Laboratory, Air Force Systems Command, Wright-Patterson AFB, Ohio.

Shoop, S.A., Richmond, P.W., Eaton, R.A., 2001. Estimating rolling friction of loose soil for aircraft takeoff on unpaved runways. ERDC/CRREL TR-01-11. Hanover, NH: US Army Cold Regions Research and Engineering Laboratory. 
Shoop, S.A., Diemand, D., Wieder, W.L., Mason, G., Seman, P.M., 2008. Predicting california bearing ratio from trafficability cone index values. ERDC/CRREL TR08-17. Hanover, NH: US Army Corps of Engineers - Engineer Research and Development Center.

Taylor, R.P., Godley, S.A., 2008b. Minimising the likelihood and consequences of runway excursions. An Australian perspective. ASTB Final report AR-2008 018(2). Canberra City, ACT. Australian Transport Safety Bureau, Aviation Research and Analysis.

Taylor, R.P., Hughes, K., Godley, S.A., 2008a. Runway excursions: Part 1 - A worldwide review of commercial jet aircraft runway excursions Worldwide review of commercial jet aircraft runway excursions. ASTB Final Report AR2008-018(1). Canberra City, ACT. Australian Transport Safety Bureau, Aviation Research and Analysis.
U.S. Department of the Air Force - Headquarters Air Force Civil Engineer Support Agency, 2008. Structural evaluation procedure for stabilized soil-surfaced airfields. Engineering Technical Letter (Etl) 08-14.

White, J.C., Agrawal, S.K, 1993. Soft ground arresting system for airports. FAA Fina Report 93-80. Washington, DC. U.S. Department of Transportation, Federal Aviation Administration

Wong. D.K.Y.. Pitfield, D.E. Caves, R.E., Appleyard, A.J., 2009. The development of a more risk-sensitive and flexible airport safety area strategy: part II. Accident location analysis and airport risk assessment case studies. Safety Science 47 (7) 913-924. 